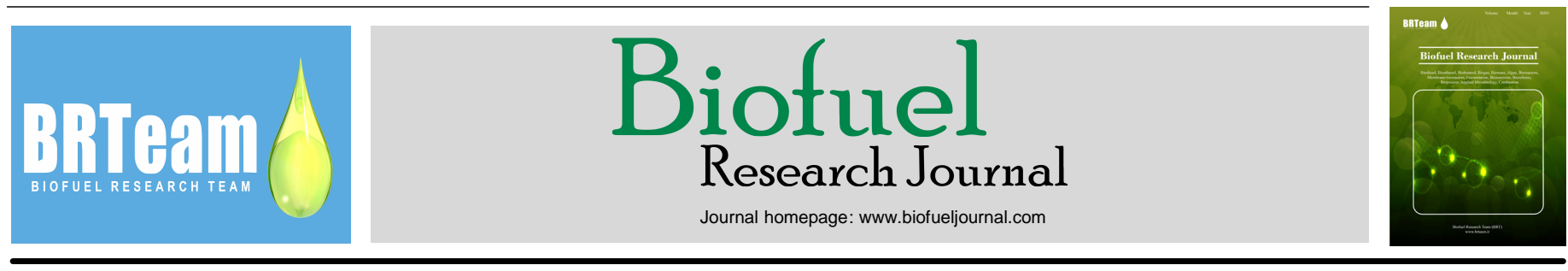

Editorial

\title{
Preventing the progression of climate change: one drug or polypill?
}

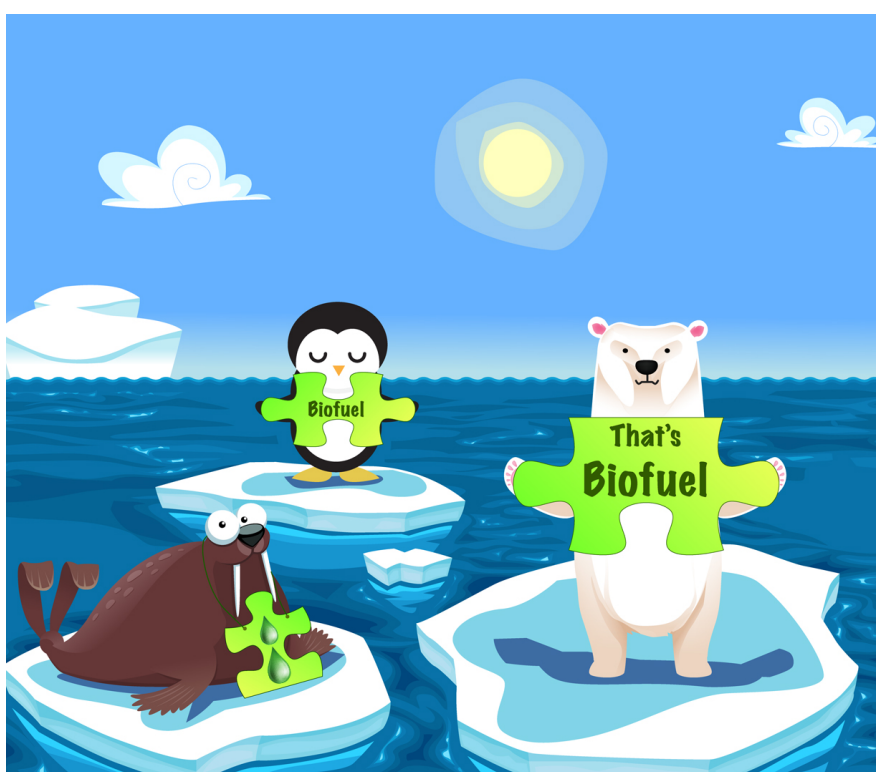

Amongst credible scientists, some facts are not in doubt. The role of 'greenhouse gases' (GHGs) in warming our plant, and the associated reality of human-driven climate change, are fully accepted. So, too, is the longevity of the results of inaction: $15 \%$ of $\mathrm{CO}_{2}$ emitted today will still be warming our planet 10,000 years from now, and $7 \%$ of it doing the same in 100,000 years (Archer, 2005). Likewise, the grave consequences of climate change to the human condition are also accepted. Impacts can be direct through infectious disease change (through impacts on bacterial growth rates; extreme weather events leading to sewerage water contamination; altered distributions, breeding and feeding cycles of parasitic vectors, and of parasite growth rates); water toxicity (algal blooms, water contamination); or altered air quality (ground level ozone, particulates from fires consequent upon drought). They can also be indirect (for instance, through starvation due to extreme weather events, or population displacement and conflict) (Watts et al., 2015).

What is less certain is the trajectory which our planet will follow as climate change progresses. This uncertainty relates to four elements: the degree and speed with which society responds by reducing emissions; the confidence intervals surrounding projected temperature rises (amplified by uncertainty over the impact of non-linear multipliers- the 'positive feedback loops'); the physical consequences of such warming (through extreme weather events, for instance); and the gearing and complex relationship between these effects and their societal consequences. This said, lack of certainty is misrepresented: the grave consequences of continued GHG emissions are certain, even if the depth of gravity is not. Debating 'quite how very bad things might be' is thus something of a distraction.
But what is the route to decarbonisation? For every advocate, there is a critic. Nuclear is criticised for its toxic waste, and risks related to terrorist availability of fissile or harmful materials, or reactor instability. Renewable deployment is criticised for problems in managing base load and matching supply to demand. Carbon capture and storage are said to be a long way from large-scale applicability.

What, then, of biofuels? Certainly, the modelling of 'Representative Concentration Pathway' (RCP) 2.6- that which offers the best hope of keeping global temperature rise to less than $2^{\circ} \mathrm{C}$ above preindustrial levels- is built upon extensive use of biofuels. However, critics argue that land devoted to their growth restricts that available and necessary for food production, and that they are less effective in climate change mitigation than often propounded, given emissions related to direct (DLUC) and indirect land use changes (ILUC) (Khanna et al., 2011). Biofuel crops may also be every bit as threatened by climate change-related extreme weather events as are conventional crops. Such arguments may have some merit. However, the world of biofuels is, as this journal shows, not static. What could energy crops genetic engineering have to offer? Or the use of artificial photosynthesis for biofuels production?

So how should we proceed? Perhaps a medical analogy is of value. Doctors are often faced with scenarios in which rapid intervention is mandated, without which descent to death is certain. The nature of the required interventions is not known with certainty, but is rarely singular. Doctors are not paralysed into inaction: a multidisciplinary team confers, and together they move swiftly, based upon best evidence, and apply a full suite of treatments at speed. Later, as the patient begins to recover, those interventions of lesser value are withdrawn. It is time for a similar pragmatic response to the threat posed by climate change.

\section{References}

[1] Archer, D., 2005. Fate of fossil fuel CO2 in geologic time. J. Geophys. Res. 110(C09S05)

[2] Watts, N., Adger, W.N., Agnolucci, P., Blackstock, J., Byass, P., Cai, W., Chaytor, S., Colbourn, T., Collins, M., Cooper, A., Cox, P.M., 2015. Health and climate change: policy responses to protect public health. The Lancet. 386(10006), 1861-1914.

[3] Khanna, M., Crago, C.L., Black, M., 2011. Can biofuels be a solution to climate change? The implications of land use change-related emissions for policy. Interface Focus. 1(2), 233-247. 